International Journal of Automotive and Mechanical Engineering ISSN: 2229-8649 (Print); ISSN: 2180-1606 (Online)

Volume 15, Issue 1 pp. 5002-5021 March 2018

(C) Universiti Malaysia Pahang, Malaysia

DOI: https://doi.org/10.15282/ijame.15.1.2018.9.0388

\title{
Variation of Drag Coefficient, Wall Static Pressure and Secondary Flow Over Passenger Car
}

\author{
Ajitanshu Vedrtnam* and Dheeraj Sagar \\ Department of Mechanical Engineering, Invertis University, \\ Bareilly, UP, India-243001 \\ *Email: ajitanshu.m@invertis.org \\ Phone: +918979693576; Fax: +91532 2271200 \\ Department of Applied Mechanics, Motilal Nehru National Institute of Technology \\ Allahabad, Allahabad, UP, India-211004.
}

\begin{abstract}
The present experimental investigation includes finding the variation of drag coefficient, wall static pressures, and aerodynamic drag over a vehicle for twenty-six different orientations of vehicle. The flow was controlled using the submerged type vortex generator (VG) in combination with the rear spoiler during the investigation. The model of a vehicle was fabricated on the reducing scale (15:1) using the Plaster of Paris (PoP). Primarily, the vehicle was tested at the different incidence yaw angles to obtain the total drag over the model. Further, twenty-six different combinations obtained by changing the flow angles $\left(\beta=0\right.$ and $\left.\pm 30^{\circ}\right)$, spoiler angles $\left(\alpha=0\right.$ and $\left.\pm 45^{\circ}\right)$ and orientations of VGs were tested. A variation of static pressures and drag coefficients for all combinations was analyzed. Further, the development of secondary-flow was also traced. Secondary flow becomes important as it causes a sheared flow produced near the body and wall of a sadden vehicle which further deflects the air pressure on the roof of the vehicle body. The variation of the secondary flow was obtained with the wall static pressure, surface static pressure and boundary layer by changing the flow angles $\left(\beta=0\right.$ and $\left.\pm 30^{\circ}\right)$, and spoiler angles $\left(\alpha=0\right.$ and $\left.\pm 45^{\circ}\right)$ and orientations of VGs. The best combination in terms of surface static pressure coefficient (Cwp) rise (from -0.041 to +2.622 ) is found at $\beta=0^{\circ}, \alpha=0^{\circ}$ and the VG attached to the upstream of the spoiler. CFD analysis is conducted using ANSYS FLUENT ${ }^{\circledR}$ and Solid Works was used for building the geometries of the car and spoiler. A formulated computational fluid dynamics model is in good match with the experimental results.
\end{abstract}

Keywords: Aerodynamics; drag reduction; flow control; boundary layer control.

\section{INTRODUCTION}

The modification of the shape of the cars for reduction of drag coefficient (CD) is discussed widely [1]. The streamlined shaped modern cars have more than $50 \%$ lower CD value in comparisons to old box-type cars [2]. The flow separation is predominantly observed in high-speed passenger cars on the rear window and on the wheel base [3]. The rear part of the car contributes $80 \%$ of the total aerodynamic drag [4]. The angle of taper at the rear end and the roundness of the front corners of a bluff object have the major influence on the CD [5]. The rear taper in passenger cars (spoiler) is built-in for the passenger cars at the trunk rear to reduce drag [6]. Rear spoilers delay the flow separation for decreasing 
drag. Safety and stability to cross-wind interaction were also discussed in the literature; vehicles may lose stability with stronger cross-flow of the wind [7].

A number of studies [8-35] are reported in the literature for the drag reduction. Geropp and Odenthal reported the rise in base pressure by $50 \%$ and total drag reduced by $10 \%$ after the flow control [19]. Koike et al. have found that the flow separation near the rear end of the sedan vehicles is the main cause of aerodynamic drag and the flow separation can be delayed by using vortex generators (VG) on the roof end of a sedan [20]. The delta-wing-shaped VG was later used as an accessory for sedan cars. Computational analysis is carried out by Singh et al. for the two-dimensional truck body using 'FLUENT' and effect of a moving body on aerodynamic drag was shown. A $35 \%$ reduction of aerodynamic drag is reported by the authors using this method [21]. Comparative study on a clay model (scale 15:1) of the small hybrid car is performed following two different experimental procedures of aerodynamic predictions, one relying on pressures downstream and upstream of car model and the other on distribution of pressure along the center line of the model. The experimentation was followed by computational analysis using the 'FLUENT' software. Drag coefficient was reported as 0.4 for $\mathrm{Re}=2.2 \times 105$ [22]. Gohlke et al. investigated the effect of the side-wind sensitivity of the trucks and cars experimentally. A 6 to $17 \%$ drag reduction is observed when the two flaps were used [23]. Beaudoin achieved flow control using moving flaps over a classic 3D bluff-body. Few configurations have resulted-in $25 \%$ drag reduction and 105 $\%$ lift reduction [24]. Gillieron has performed a study on the separation control to reduce consumption and the gas emissions to greenhouse effect of the future motor vehicles [25, 26]. Katz studied aerodynamics and different aspect of car design [27]. Computational analysis to reduce the drag is also discussed widely in the literature cited [28-35]. Drag reduction studies are also reported frequently for variety of applications other then moving vehicles [36-41].

The present work includes developing a method of flow control at the downstream of the car by optimizing surface static pressure and aerodynamic drag. The clay model of 15:1 reduced scaled geometrically similar car (Figure 1) and dynamically similar flow situations were used for the experimentation. The spoiler (at vehicle's rear end) and VG (on the roof end) were used for controlling the flow and zone of the flow separation. A study of flow visualisation was also performed using tufts on model surface. The later section includes the discussion on development of secondary-flow. The secondary flow contain vorticity that causes a motion of the fluid particles, which is not essentially restricted to involve motion of the fluid particles along the streamlines of the potential flow but can define other streamlines. Secondary flow is produced when a stream wise component of vorticity is developed from the deflection of an initially sheared flow. Secondary flow is also noticed when a sheared flow passes over vehicle of definite thickness, or when a boundary layer meets an obstacle normal to the surface over which it is flowing (e.g. a wind blowing past over on a vehicle). The cited literature does not include any study related to secondary flow for a passenger vehicle. Finally, CD is obtained for all 26 combinations using CFD analysis for validation of experimental results.

\section{MATERIALS AND METHOD}

The experiments were mainly concerned with the boundary layer development over the surface of the car with the help of boundary layer probe, to reduce the drag coefficient by controlling flow separation using rear spoiler and submerged type vortex generator over 
rear, and the flow visualization over car placed in a rectangular duct with the help of single point tuft.

The experiments were conducted in open circuit blow down type wind tunnel (Figure 1). The experimental setup consists of (1) driving unit (blower) (2) HighEfficiency Particulate (HEPA) filter (3) wide angle diffuser (4) settling chamber (5) contraction cone (6) small entry duct (expander) (7) rectangular test section. The delivery at the delivery pressure of $0.6 \mathrm{~m}$ of the water column was achieved using a single stage 'SMW' make centrifugal blower with a capacity of $0.6 \mathrm{~m}^{3} / \mathrm{s}$. A Compton Greaves make $11 \mathrm{~kW}$ electric induction motor with a rated speed of $2920 \mathrm{rpm}$ was directly coupled to the blower. Intake airflow from the blower exit can be controlled by throttling mechanism provided at the blower inlet. A flexible coupling was used to connect the blower outlet with the conical diffuser for lesser vibrations. A HEPA filter has been used at the suction side of the centrifugal blower to trap a lot of micro particles laden in the air. It removes $99.97 \%$ of $0.3 \mu \mathrm{m}$ diameter airborne particles. The larger or smaller particles are filtered efficiently. The discharge from the blower enters a conical diffuser of length $2.0 \mathrm{~m}$. and having $0.22 \mathrm{~m}$. and $0.6 \mathrm{~m}$ inlet and outlet diameters respectively. The discharge from the diffuser is entered the settling chamber having $0.6 \mathrm{~m}$ diameter and $1.5 \mathrm{~m}$ length. Nylon screens were used at the three different locations within the settling chamber for straightening and the turbulence level reduction of the flow before it enters the contraction cone. A contraction cone, shaped as bell-mouth and made of fibre-reinforced plastic (FRP), having a length of $0.45 \mathrm{~m}$ was fitted at the exit of the settling chamber. It helps in achieving uniform velocity profile at the exit of the contraction cone by reducing the turbulence fluctuation. An area contraction ratio (outlet to inlet area ratio) of 64:1 ensures a nearly uniform and low turbulence intensity flow at the test section entrance. A short transition type entry duct with the circular inlet of $0.075 \mathrm{~m}$ and square outlet of $0.65 \mathrm{x}$ $0.65 \mathrm{~m}$ and length of $0.15 \mathrm{~m}$ was fitted at the end of the contraction cone. It helps to fix the diffuser of inlet size of $0.65 \times 0.65 \mathrm{~m}^{2}$. The test section was made with transparent Perspex sheet. It has an outer dimension of $300 \times 300 \times 1500 \mathrm{~mm}$. The internal cross section was reduced to $300 \times 75 \mathrm{~mm}$ with the help of pairs of parabolic wooden blocks $300 \mathrm{~mm}$ long $\times 75 \mathrm{~mm}$ height and Perspex sheets. The gap of $300 \times 75 \mathrm{~mm}$ created at the top and bottom was used to keep the pressure tapping tubes untangled. To understand the flow field, several instruments were used to take accurate measurements. These included a telescopic pitot tube, a calibrated five-hole probe (Figure 2) with the transverse mechanism, a digital micro-manometer coupled with a pressure scanner and a digital metal vane anemometer.

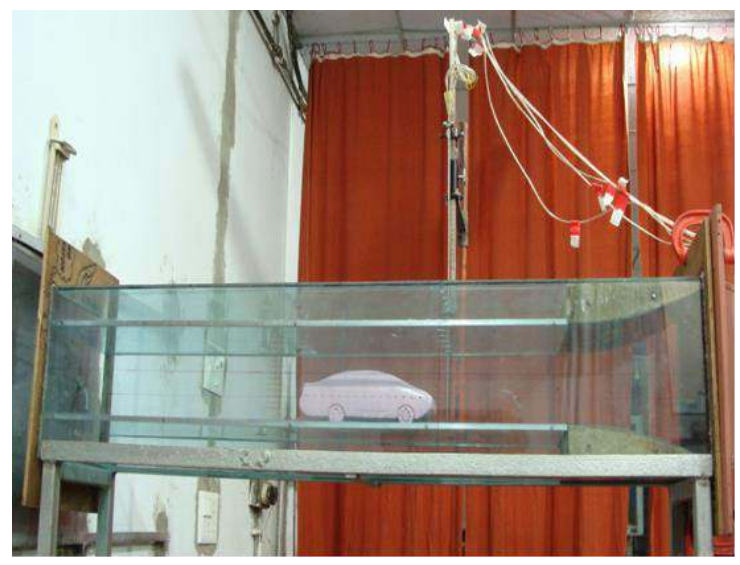

Figure 1. Test section with test piece mode. 


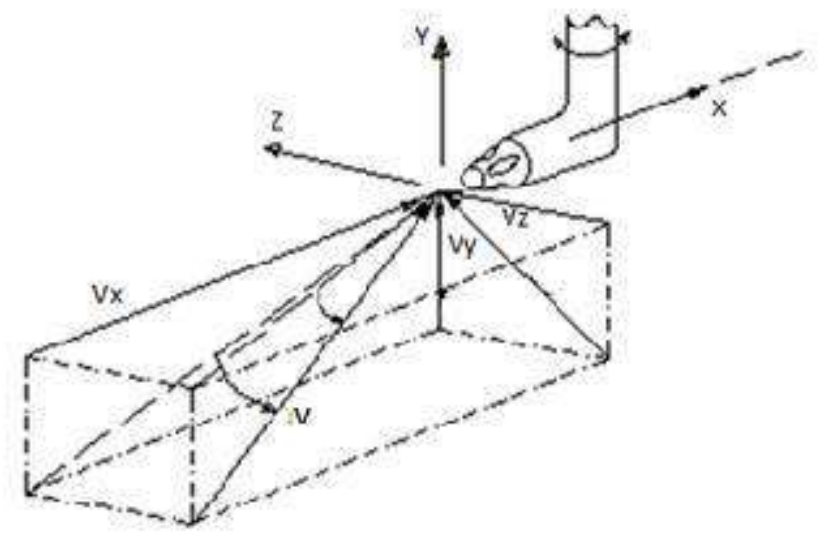

Figure 2. Schematic diagram of the five-hole probe.

The metal vane anemometer was used to measure the velocity at the exit of the test section. For the inlet, the telescopic pitot tube was used as it was easier to insert and less bulky. The pressure measurement in the area of interest was achieved with the calibrated five-hole probe. It was position using rack and pinion traversing mechanism. The pressure was measured with the digital micro manometer. The spoiler is fabricated using perspex sheet is attached at the rear of the car model for reducing the drag. Two mounting struts were used to fix the spoiler. Figure 3 shows the different orientation of the spoiler used in the study. The VGs are designed considering the boundary layer thickness. The flow visualization over the car placed in a rectangular test section with the help of woolen tufts. Rear vortices tufts study and surface tufts study were performed. Rear vortices tufts study used a rectangular shaped of $300 \times 160 \mathrm{~mm}$ and were fabricated as net plate using in the back side of the car at velocities of 15 and $30 \mathrm{~m} / \mathrm{s}$ and were attached with 392 tufts of each node. Each node has woolen tufts in size of $25 \mathrm{~mm}$ long. For surface tufts study, the surface of the car is divided in the four sections as the front, roof, the rear part of the car body and two sides of the car. Each section was having 25 $\mathrm{mm}$ long woolen tufts. Sixty-three blue colored woolen tufts on front, fifty-three yellow colored tufts on the roof, thirty-six black in the rear and one-hundred-twenty-four red colored tufts were pasted on each side of the car model. The video and photographs were taken for different test conditions, viz. (a) Car at $0^{\circ}$ with different velocities of 10, 20 and $30 \mathrm{~m} / \mathrm{s}$ (b) Car at $(-\mathrm{ve})\left(10^{\circ}, 20^{\circ}, 30^{\circ}\right)$ windward side at velocities 10,20 and $30 \mathrm{~m} / \mathrm{s}$ and; (c) Car at (+ve) $\left(10^{\circ}, 20^{\circ}, 30^{\circ}\right)$ windward side at velocities 10,20 and $30 \mathrm{~m} / \mathrm{s}$.

Figure 4 (a) represents the velocity profile on the model's center-line plane. The gradually lower height of model due to downstream flow results-in expanded airflow causing rise in downstream pressure, further a reverse flow against the main flow. Whereas, the lower region near to the vehicle's surface the airflow quickly loses momentum due to the viscosity of air as it moves downstream. Figure 4 (b) shows the flow around VG located just before the separation point (used for supplying momentum from higher to lower region) causes separation point to shift further downstream. Thus, the expanded flow continues longer, flow velocity becomes slower and static pressure becomes higher. In Figure 4 (c), velocity profile on the model's roof, optimum height of VG has regulated accordingly. However, shifting separation points works up to a limit, thus an optimum level is investigated in the present study. 


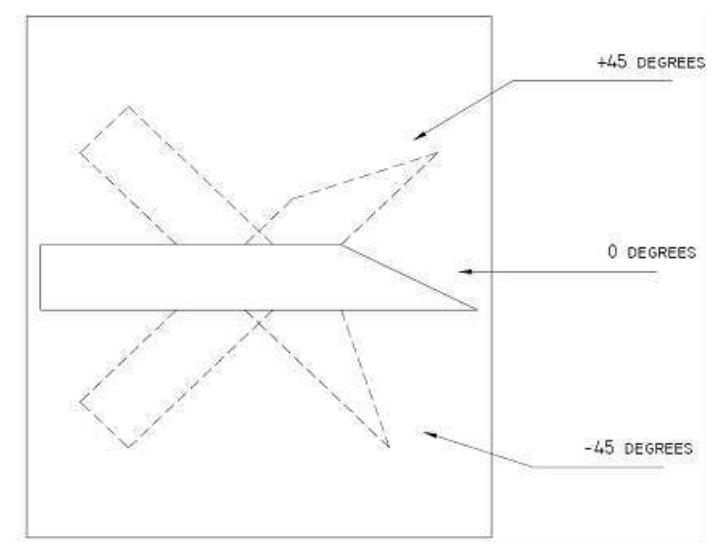

Figure 3. Different orientation of the spoiler

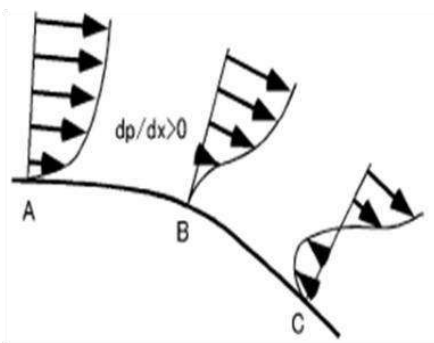

(a)

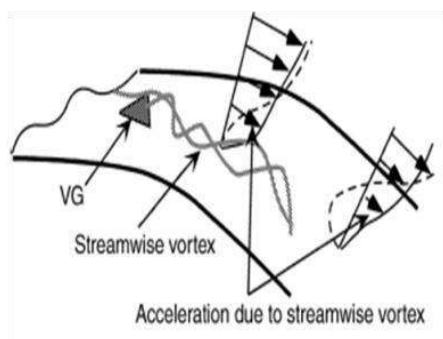

(b)

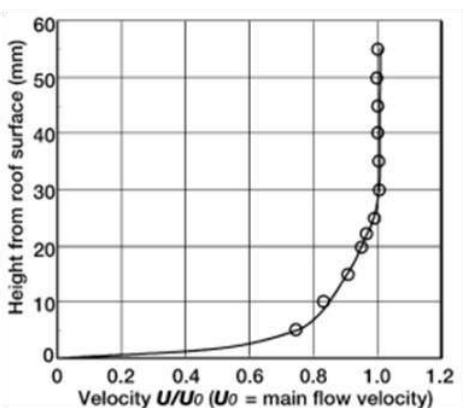

(c)

Figure 4. Velocity profile on (a) the model's center-line plane (b) around VG and; (c) the model's roof.

\section{RESULTS AND DISCUSSION}

Table 1 shows the results of experimentation after testing twenty-six combinations obtained by different flow angles, spoiler angles and the orientations of VG. Figure 5 shows the boundary layer growth over the car surface at upstream $(x / L=0)$, downstream $(\mathrm{x} / \mathrm{L}=1.0)$ and midstream $(\mathrm{x} / \mathrm{L}=0.5)$ at $30 \mathrm{~m} / \mathrm{s}$ upstream flow velocity and $\beta=0^{\circ}$. It is found that the boundary layer thickness is $2 \mathrm{~mm}$ in the mid-stream, and $3 \mathrm{~mm}$ in the downstream location. The boundary layer thickness was used for designing the VG. The VGs were located on the rear windshield along the car width $(\mathrm{x} / \mathrm{L}=0.733)$. The maximum height of the VG $(2.0 \mathrm{~mm})$ is less than the boundary layer thickness existing at this plane $(\mathrm{x} / \mathrm{L}=0.733)$. As the VGs are immersed in the boundary layer, they referred to as 'submerged vortex generators' (SVGs).

Forty-seven static pressure tapings are provided along the vehicle length on the left side, right side, and vehicle roof. At $\beta=0^{\circ}$, the spoiler and VG does not affect the axial distribution of surface pressure (Figure 6). At $\beta= \pm 30^{\circ}$, the windward sides (which confronts with the airflow) receive the positive static pressure for most of the vehicle length, while the leeward sides (which is away from the airflow), further suction is recorded. 
Table 1 Results of experimentation.

\begin{tabular}{|c|c|c|c|c|c|}
\hline $\begin{array}{l}\text { Sl. } \\
\text { No. }\end{array}$ & $\begin{array}{l}\text { Vehicle Configuration at } \\
\text { different } \beta \text { and spoiler angles }\end{array}$ & $\begin{array}{l}\text { Ptp_down } \\
\mathrm{MPa}\left(10^{-6}\right)\end{array}$ & Ctp_down & Cwp & $\mathrm{Cd}$ \\
\hline 1 & Vehicle facing the wind $(0)$ & 318.98 & -0.217 & -0.041 & 0.360 \\
\hline 4 & Vehicle in Cross-wind $(+30)$ & 405.77 & -0.053 & -0.007 & 0.436 \\
\hline 3 & Vehicle in Cross-wind (30) & 433.75 & -0.001 & 0.051 & 0.499 \\
\hline 4 & Vehicle (0) with Spoiler (0) & 294.39 & -0.263 & -0.002 & 0.289 \\
\hline 5 & Vehicle (0) with Spoiler $(+45)$ & 308.55 & -0.237 & 0.065 & 0.326 \\
\hline 6 & Vehicle (0) with Spoiler $(-45)$ & 277.68 & -0.295 & 0.058 & 0.341 \\
\hline 7 & Vehicle $(+30)$ with Spoiler $(0)$ & 397.40 & -0.069 & 0.034 & 0.299 \\
\hline 8 & Vehicle $(+30)$ with Spoiler $(+45)$ & 463.19 & 0.055 & 0.030 & 0.371 \\
\hline 9 & Vehicle $(+30)$ with Spoiler $(-45)$ & 356.42 & -0.08 & 0.112 & 0.371 \\
\hline 10 & Vehicle $(-30)$ with Spoiler $(0)$ & 801.00 & 0.692 & 0.053 & 0.348 \\
\hline 11 & Vehicle $(-30)$ with Spoiler $(+45)$ & 477.63 & 0.082 & 0.053 & 0.205 \\
\hline 12 & Vehicle (-30) with Spoiler (-45) & 356.42 & -0.146 & 0.065 & 0.468 \\
\hline 13 & $\begin{array}{l}\text { Vehicle }(0) \text { with Spoiler }(0) \text { and } \\
\text { Co-rotating VG }\end{array}$ & 373.29 & -0.115 & 2.622 & 0.274 \\
\hline 14 & $\begin{array}{l}\text { Vehicle }(0) \text { with Spoiler }(0) \text { and } \\
\text { Counter-rotating VG }\end{array}$ & 349.19 & -0.16 & 1.506 & 0.307 \\
\hline 15 & $\begin{array}{l}\text { Vehicle }(0) \text { with Spoiler }(+45) \\
\text { and Co-rotating VG }\end{array}$ & 318.71 & -0.217 & 0.039 & 0.326 \\
\hline 16 & $\begin{array}{l}\text { Vehicle }(-30) \text { with Spoiler }(+45) \\
\text { and Co-rotating VG }\end{array}$ & 523.12 & 0.168 & 0.051 & 0.159 \\
\hline 17 & $\begin{array}{l}\text { Vehicle }(+30) \text { with Spoiler }(+45) \\
\text { and Co-rotating VG }\end{array}$ & 384.07 & -0.094 & 0.015 & 0.316 \\
\hline 18 & $\begin{array}{l}\text { Vehicle }(0) \text { with Spoiler }(-45) \\
\text { and Co-rotating VG }\end{array}$ & 279.90 & -0.291 & & 0.401 \\
\hline 19 & $\begin{array}{l}\text { Vehicle }(-30) \text { with Spoiler }(-45) \\
\text { and Co-rotating VG }\end{array}$ & 543.25 & 0.206 & & 0.648 \\
\hline 20 & $\begin{array}{l}\text { Vehicle }(+30) \text { with Spoiler }(-45) \\
\text { and Co-rotating VG }\end{array}$ & 479.01 & 0.085 & & 0.440 \\
\hline 21 & $\begin{array}{l}\text { Vehicle }(0) \text { with Spoiler }(+45) \\
\text { and Counter-rotating VG }\end{array}$ & 297.62 & -0.257 & & 0.404 \\
\hline 22 & $\begin{array}{l}\text { Vehicle }(-30) \text { with Spoiler }(+45) \\
\text { and Counter-rotating VG }\end{array}$ & 420.66 & -0.025 & & 0.757 \\
\hline 23 & $\begin{array}{l}\text { Vehicle }(+30) \text { with Spoiler }(+45) \\
\text { and Counter-rotating VG }\end{array}$ & 341.87 & -0.174 & & 0.507 \\
\hline 24 & $\begin{array}{l}\text { Vehicle }(0) \text { with Spoiler }(-45) \\
\text { and Counter-rotating VG }\end{array}$ & 327.70 & -0.200 & & 0.367 \\
\hline 25 & $\begin{array}{l}\text { Vehicle }(-30) \text { with Spoiler }(-45) \\
\text { and Counter-rotating VG }\end{array}$ & 451.07 & 0.032 & & 0.545 \\
\hline 26 & $\begin{array}{l}\text { Vehicle }(+30) \text { with Spoiler }(-45) \\
\text { and Counter-rotating VG }\end{array}$ & 490.06 & 0.106 & & 0.403 \\
\hline
\end{tabular}




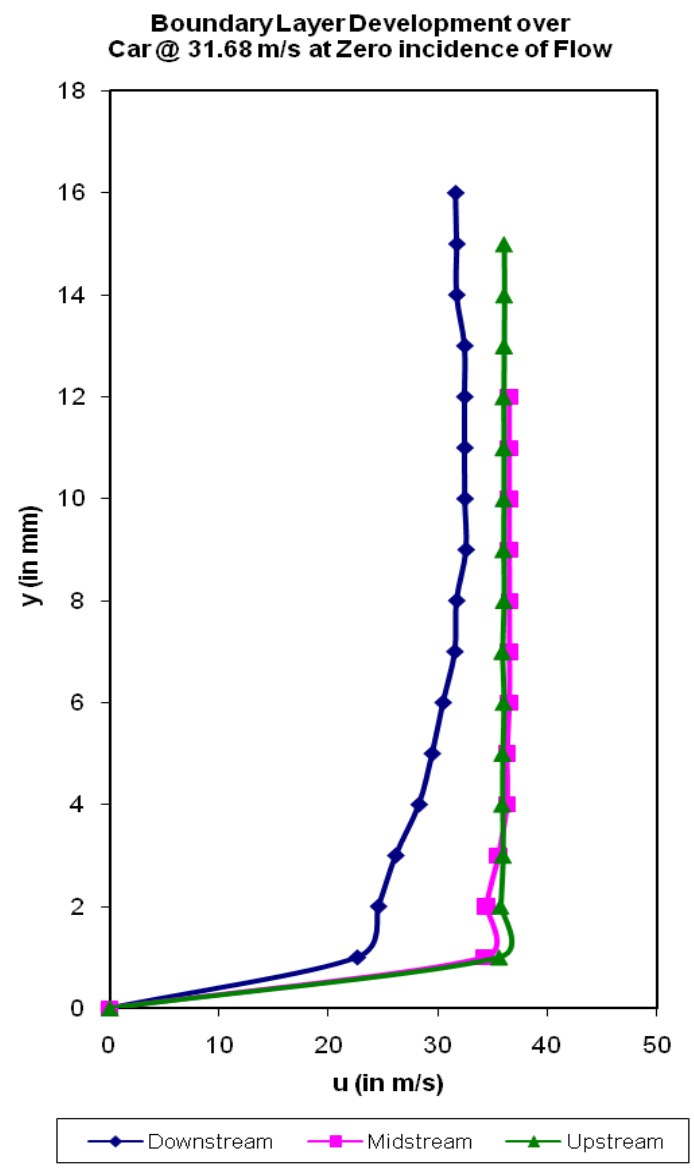

Figure 5 Boundary layer growth over the vehicle.

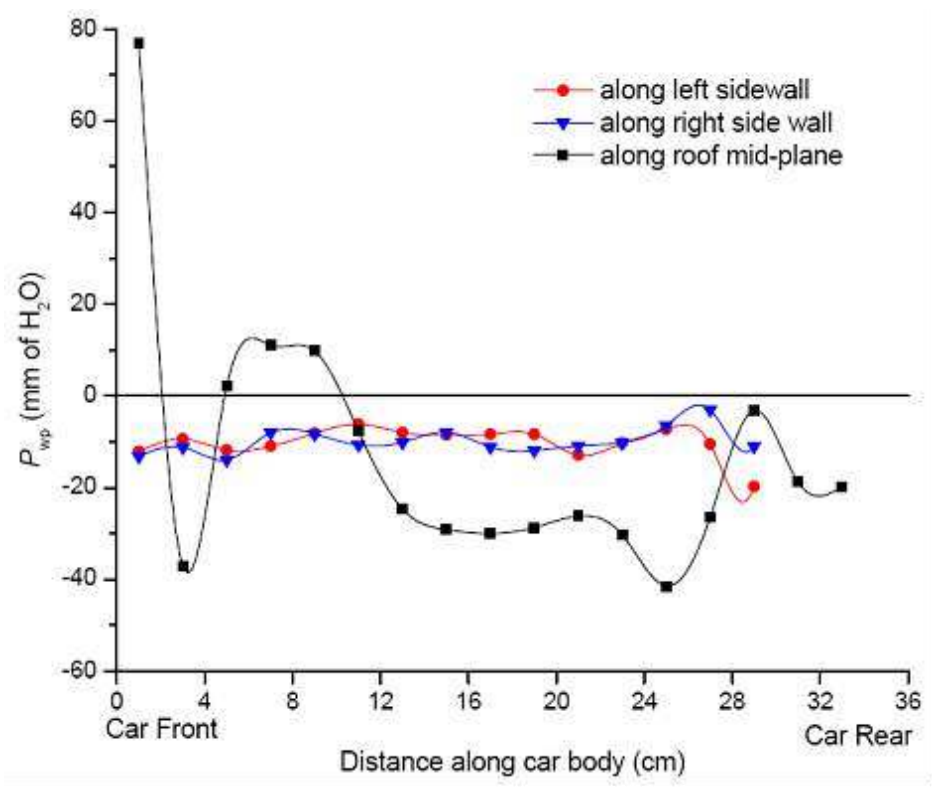

Figure 6. Surface static pressure distribution coefficient over a vehicle at $\beta=0^{\circ}$.

There is a little deviation of static pressure values for vehicle at $\beta= \pm 30^{\circ}$ due to the skewness present in the upstream air flow and a little non-symmetry involved during 
fabrication of the vehicle model. At $\beta=-30^{\circ}$, and $\alpha=+45^{\circ}$ and co-rotating VG a marked improvement in static pressure along the vehicle roof, especially at the rear is noticed. Here the suction reduces to an extent and become very close to zero static pressure values near the rear end of the vehicle. This incident clearly indicates that the flow separation zone gets reduced with the use of spoiler along with VG. Further, for $0^{\circ}$ flow angle, the whole vehicle roof is covered by suction pressure. However, for other flow angles considered for the study, it is observed that a positive pressure builds up on a little portion of the vehicle roof close to the windward side.

Figure 7 show the surface pressure coefficient contours on the vehicle Surface (without spoiler and VG) at $\beta=0^{\circ}$. It represents a symmetrical Cwp profile about midplane of the vehicle model, a smaller front area over the roof the vehicle, where static pressure remains positive, but it become negative (suction) at the rear of the vehicle roof. This may cause the flow separation at the rear portion of the vehicle. However, with the use of spoiler and combined use of spoiler and vortex generators, the negative Cwp region gets reduced, and hence the chances of flow separation become less. The best combination in terms of Cwp rise (by over 92\%) is found while the vehicle is facing wind at $\beta=0^{\circ}$ and is combined with spoiler at $\alpha=0^{\circ}$ with co-rotating VG attached at the upstream of the spoiler $(\mathrm{x} / \mathrm{L}=0.733)$.

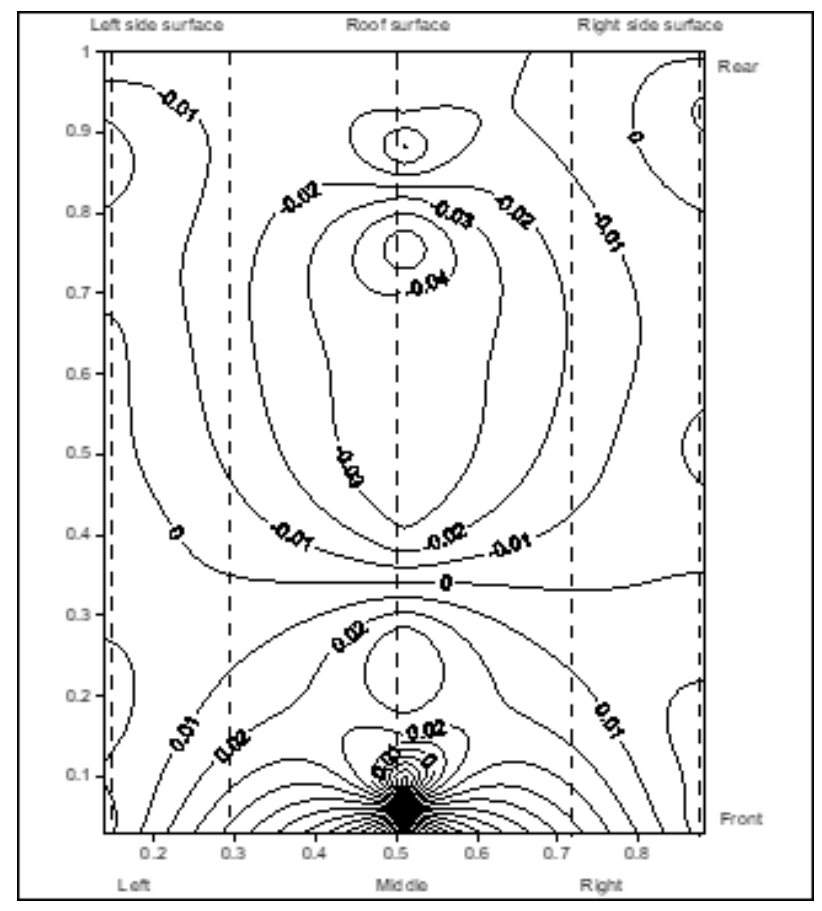

Figure 7. Surface pressure contours on the vehicle surface.

An increase in height of the VG simultaneously causes two effects: one is reduced drag resulting from delayed flow separation and the other is increased drag by the VG itself. These two effects are balanced when the VG's height is very close to the boundary layer thickness. For this reason, the maximum $\mathrm{Vg}$ height is chosen as $2 \mathrm{~mm}$. The CD for vehicle with $\beta=0^{\circ}$, is recorded as 0.36 . But the $C D$ value increases with the rise in flow angle. For $\beta=+30^{\circ}$, the $\mathrm{CD}$ value is found as 0.436 and the same for $\beta=-30^{\circ}$ is calculated as 0.499 . When the vehicle is at cross-wind condition $\left( \pm 30^{\circ}\right)$, a $36.36 \%$ more area is exposed to the direct wind. As a result, the $\mathrm{CD}$ value increases up to $38.61 \%$. The rear 
spoiler not only increases the downforce, but it also helps in reducing $\mathrm{CD}$, if attached to the vehicle at a proper angle. It is found that for a vehicle at a flow angle $=-30^{\circ}$, the CD values are decreased by $30.32 \%$ and $58.84 \%$, if attached with a rear spoiler at an angle of 0 and $-30^{\circ}$ respectively with the horizontal plane. The spoiler helps in deflecting the fluid flow smoothly, thereby reduces the net drag values to a great extent. The VG energize the decelerating fluid, and hence delay the flow separation point to further downstream. It is found from the experiments that the vortex generators, if used in combination with the rear spoiler (with $\alpha=0$ and $+45^{\circ}$ ) can decrease CD value further. However, for the vehicle with flow angle $\beta=0^{\circ}$ and with a rear spoiler of $\alpha=+45^{\circ}$, combined with the co-rotating orientation of the VG lined in series, it gives the best performance by reducing the CD value with an impressive $68.18 \%$. Figure 8 shows mean velocity contours on the vehicle downstream at $\beta=0^{\circ}$.

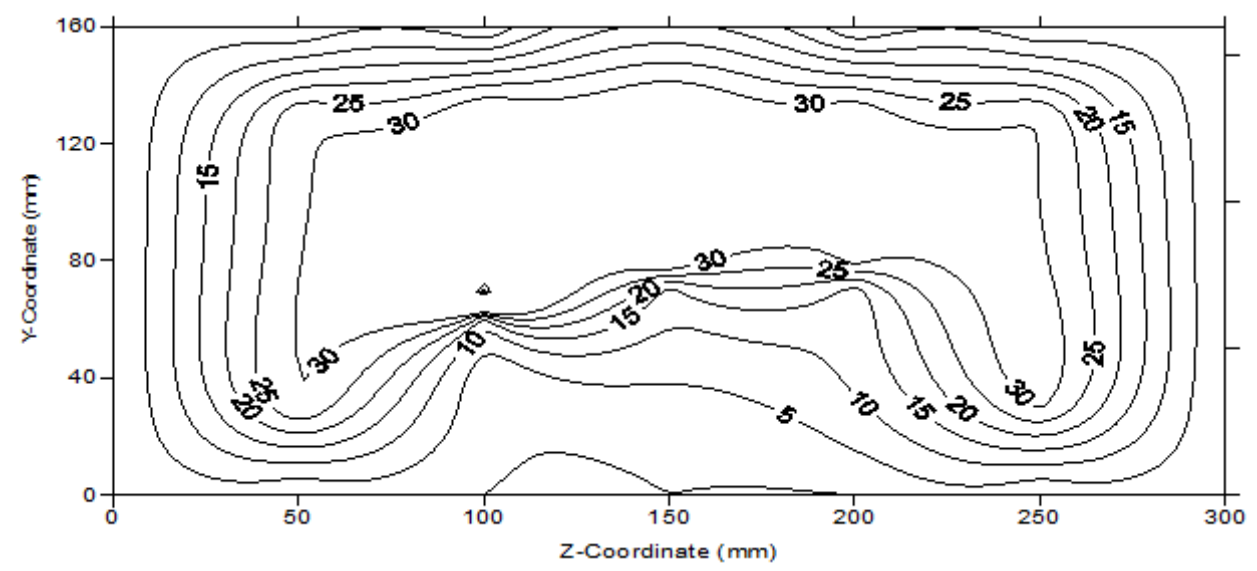

Figure 8. Mean velocity contours on the vehicle downstream at $\beta=0^{\circ}$

Figure 9 shows the wall static pressure distribution over the vehicle model, it clearly reflects that at the mid-position free stream the vehicle has a maximum variation of wall static pressure. The right side of the vehicle with $+30^{\circ}$ has the highest negative pressure while $-30^{\circ}$ right side has the maximum positive pressure. Contour plot and surface plots are shown in the Figure 10 (a) and (b) show the variation of center static pressure with an angle and center-line length, left-side static pressure and right-side static pressure respectively. The wall static pressure variation also verifies the condition for minimum drag coefficient.

Figure 11 and Figure 12 shows secondary velocity contours on the vehicle surface without spoiler and VG and with the spoiler and VG respectively. The secondary flow contour for the vehicle at $-30^{\circ}$ spoiler and $+45^{\circ}$ co-rotating VGs is shown in Figure 13. The variation of the secondary flow was obtained with the wall static pressure, surface static pressure and boundary layer by changing the flow angles $\left(\beta=0\right.$ and $\left.\pm 30^{\circ}\right)$, and spoiler angles $\left(\alpha=0\right.$ and $\left.\pm 45^{\circ}\right)$ and orientations of vortex generators. In the present work secondary flow has not significantly influenced the wall pressure. 


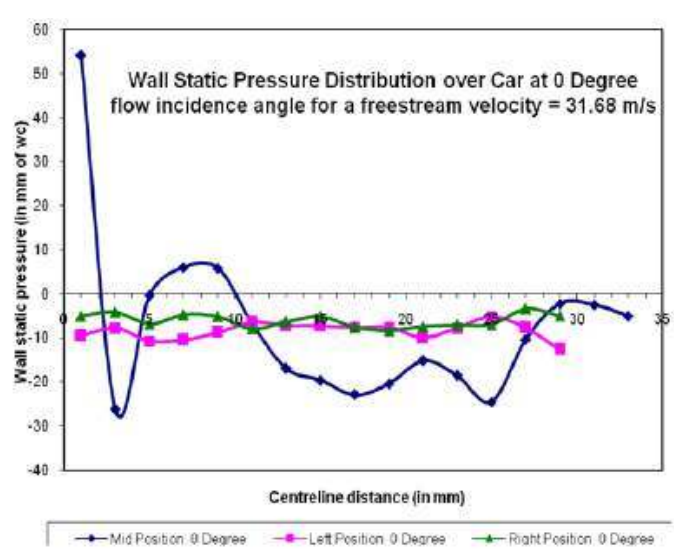

(a)

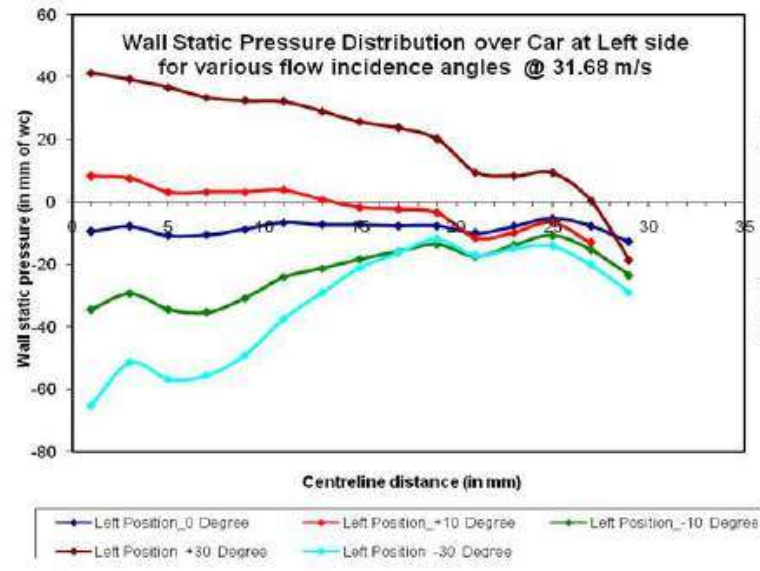

(c)

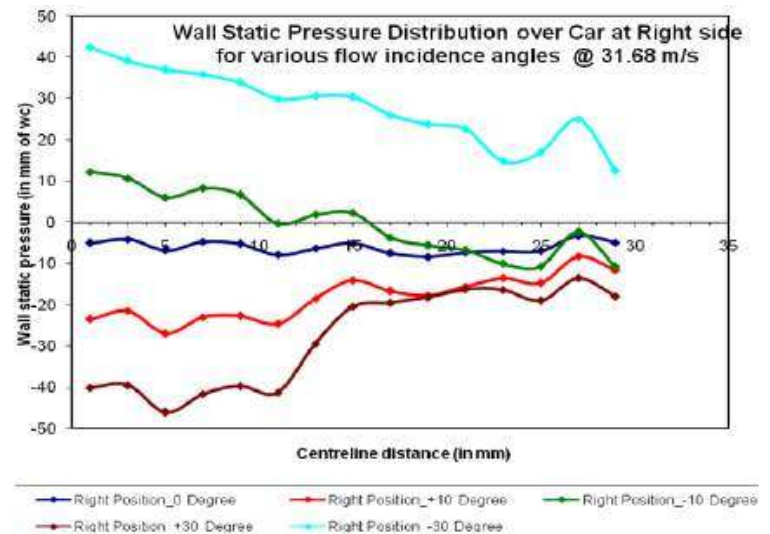

(b)

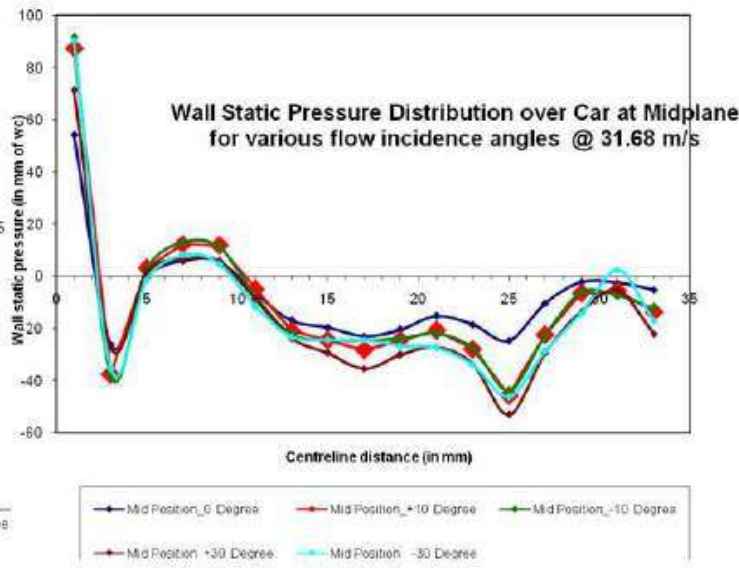

(d)

Figure 9. Wall static pressure distribution for (a) vehicle at $\beta=0^{\circ}$ (b) various values of $\beta$ at right side of vehicle (c) various values of $\beta$ at left side of vehicle (d) various values of $\beta$ at mid-plain of vehicle.

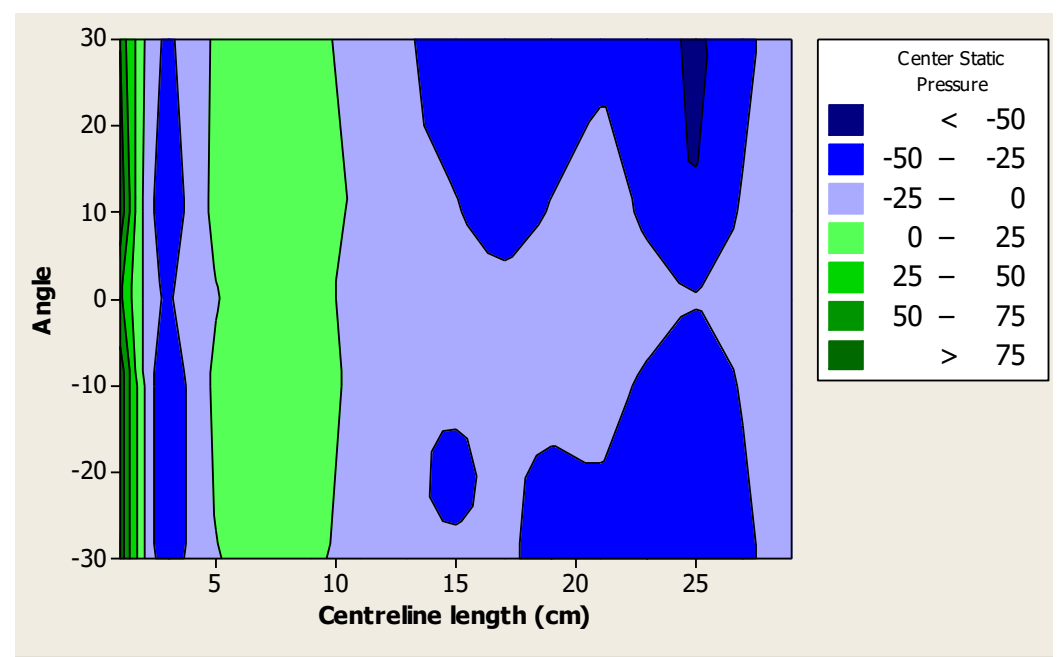

(a) 


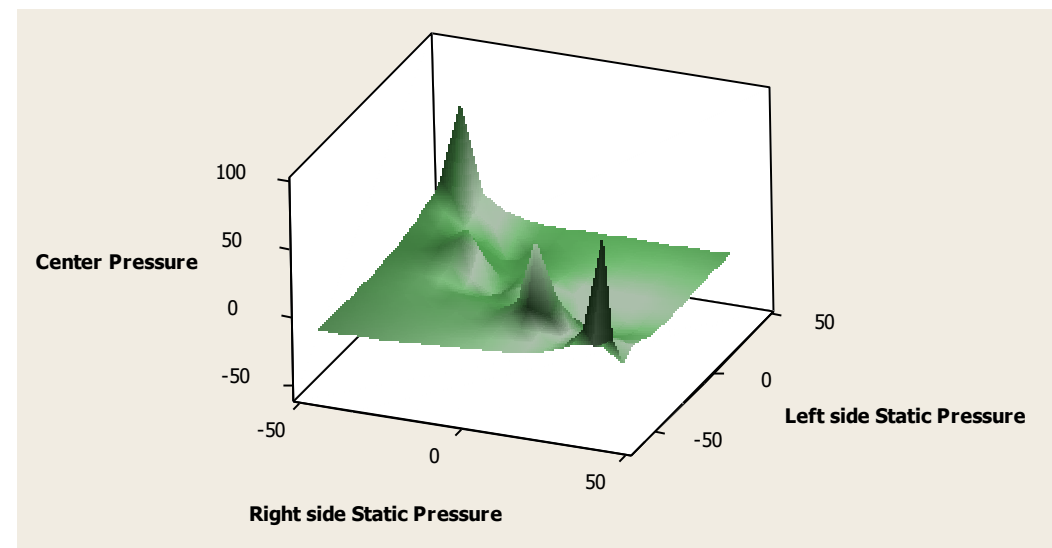

(b)

Figure 10. (a) Contour plot and (b) surface plot for center static wall pressure.

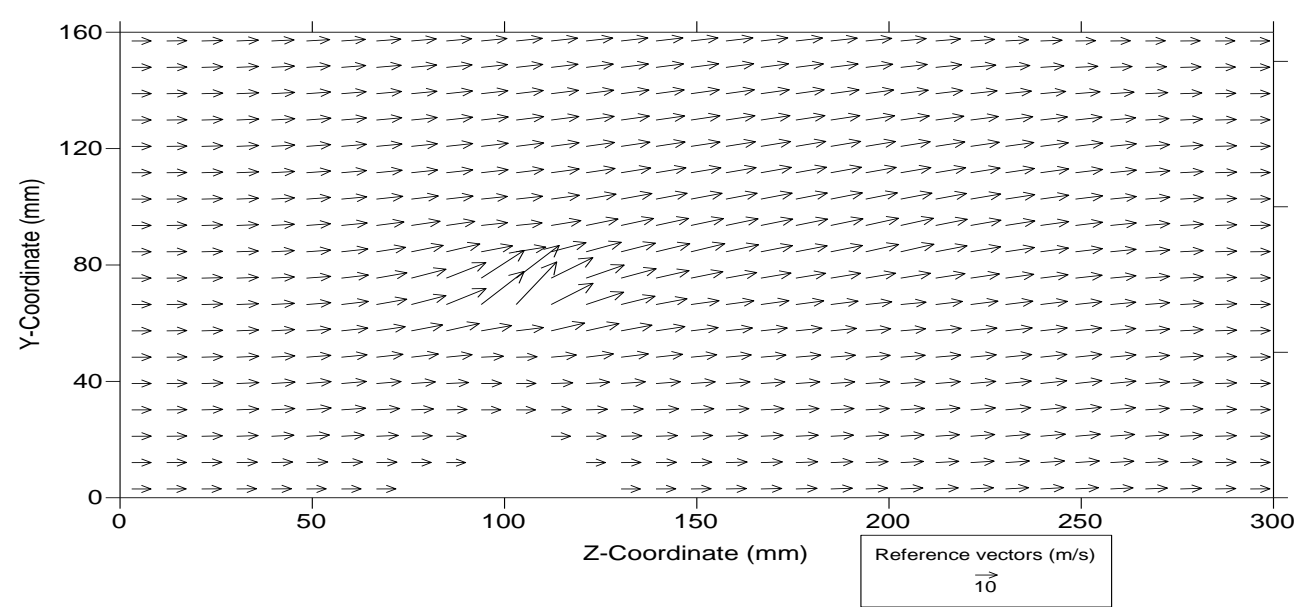

(a) vehicle at only $0^{\circ}$

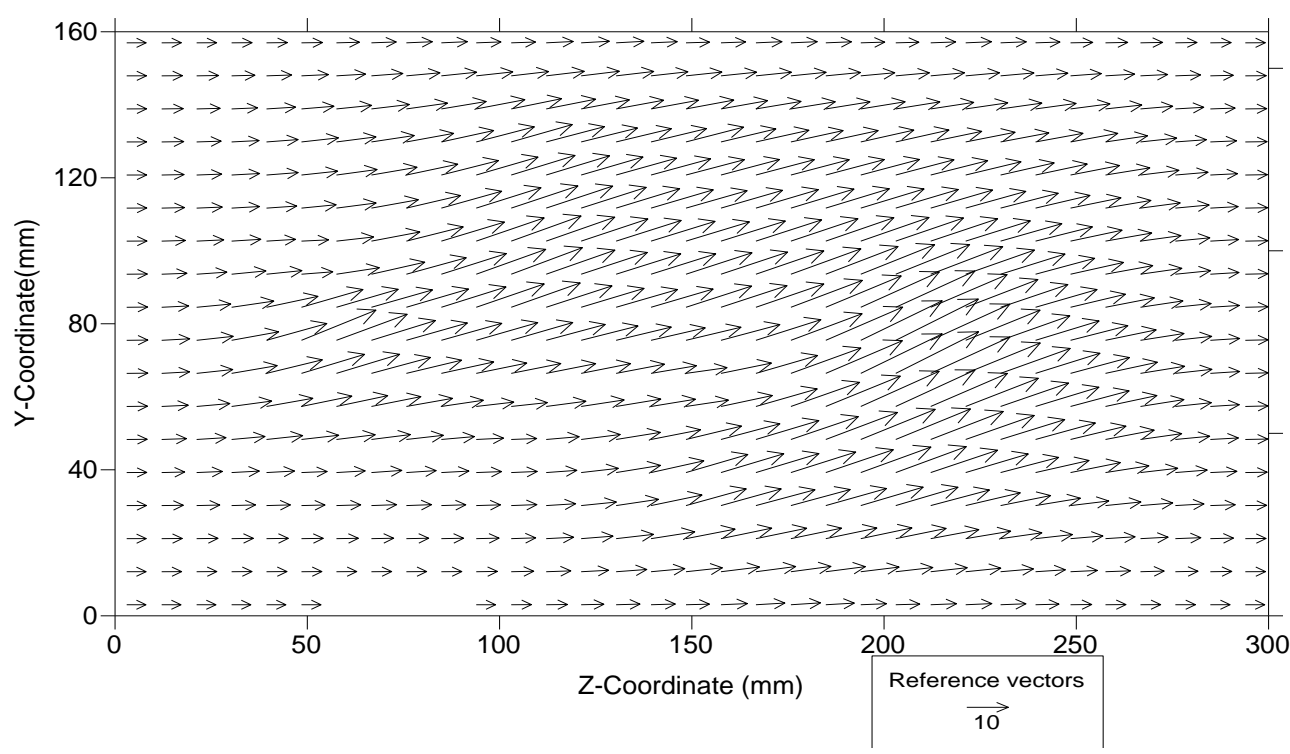

(b) vehicle at only $+30^{\circ}$ 


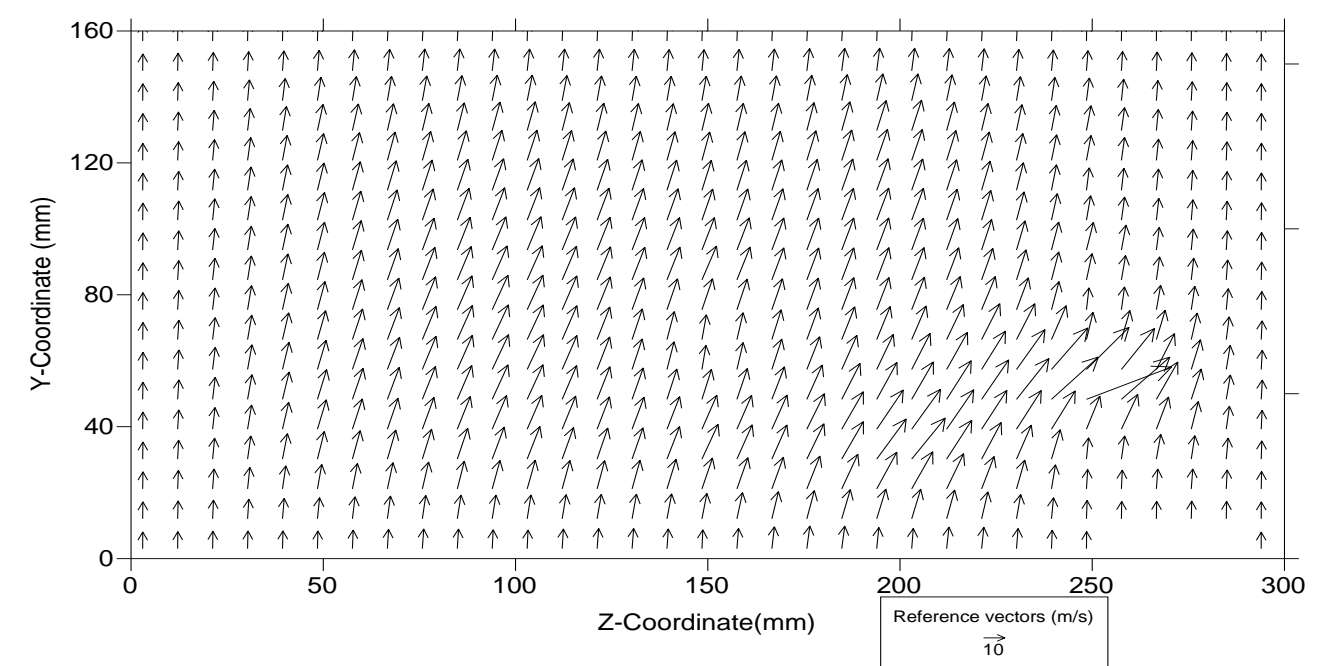

(c) vehicle at only $-30^{\circ}$

Figure 11. Secondary velocity contours on the vehicle surface (without spoiler and VG).

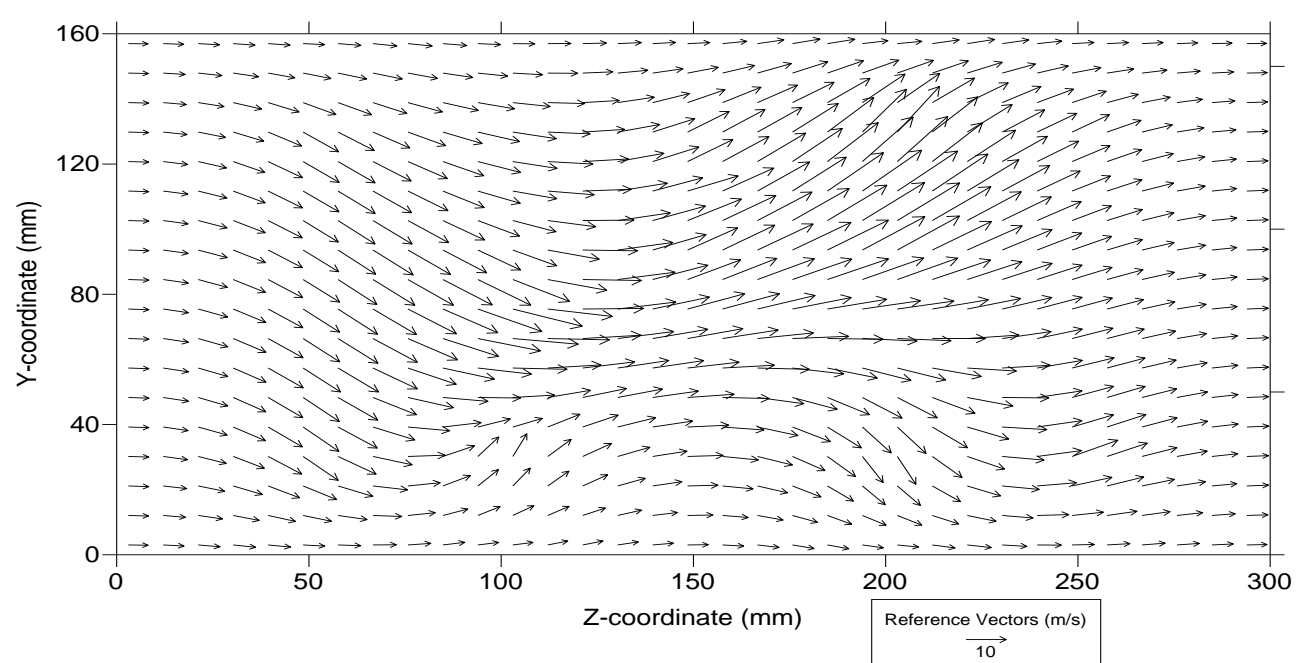

(a) vehicle $0^{\circ}$, spoiler $0^{\circ}$

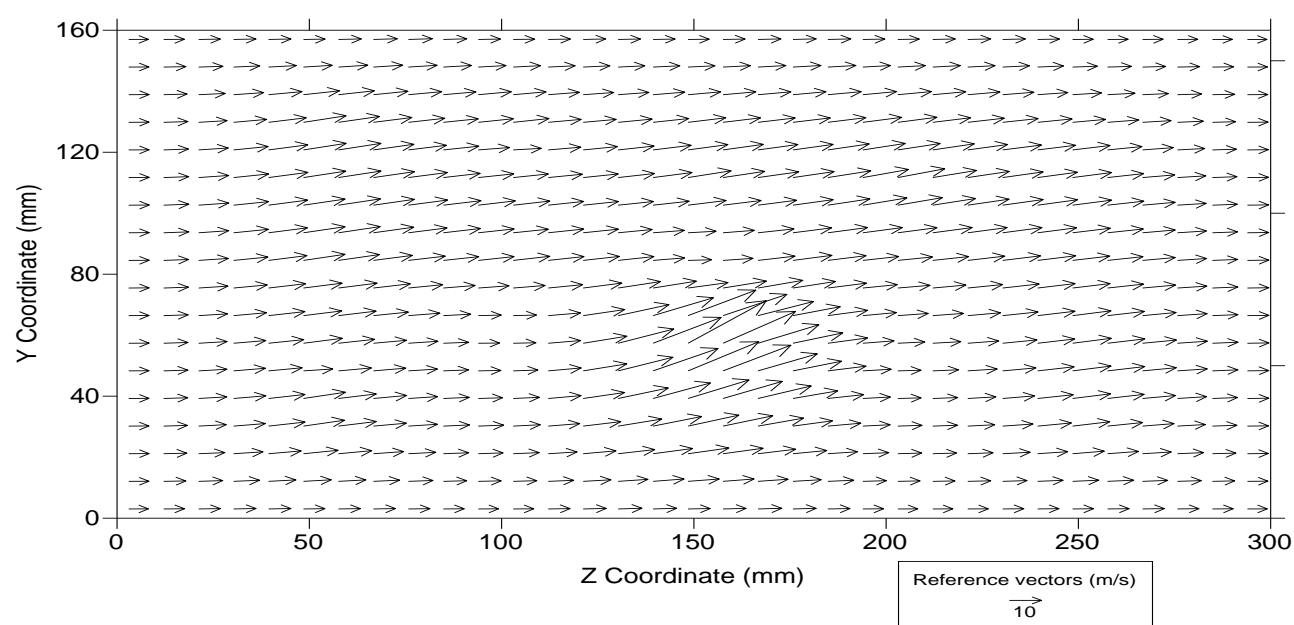

(b) vehicle $0^{\circ}$, spoiler $+45^{\circ}$ 


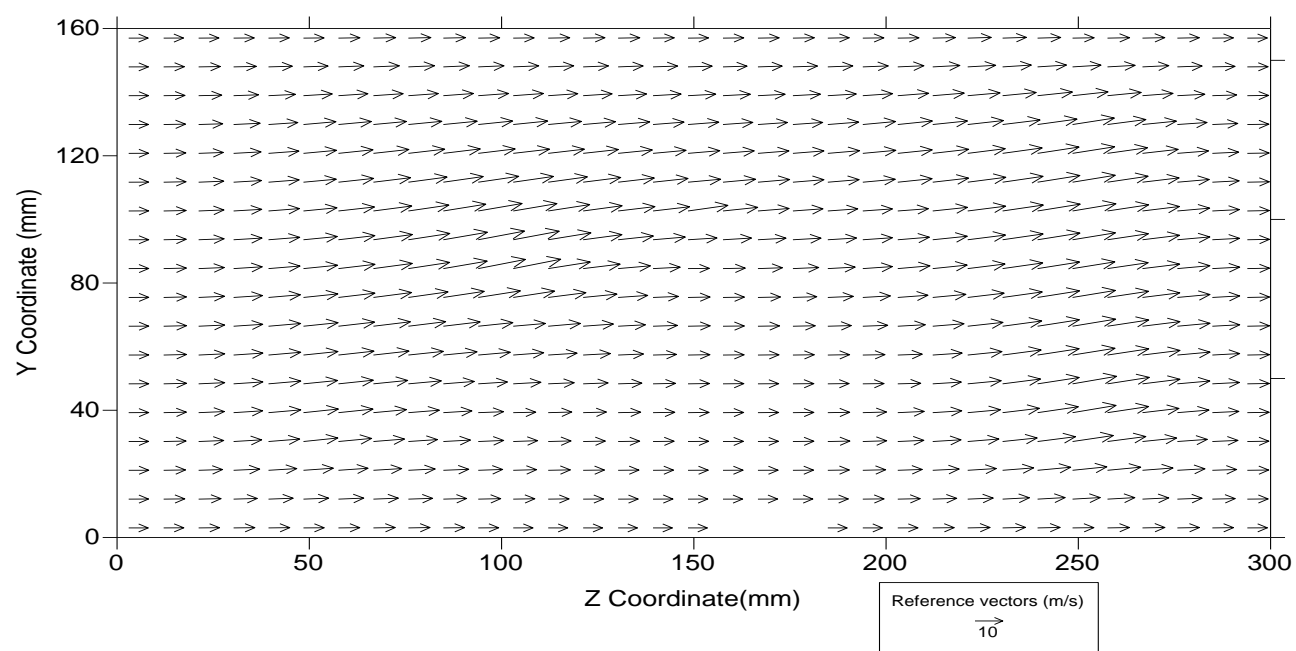

(c) Vehicle $0^{\circ}$, spoiler $-45^{\circ}$

Figure 12 Secondary velocity contours on the vehicle surface (with spoiler and without VG)

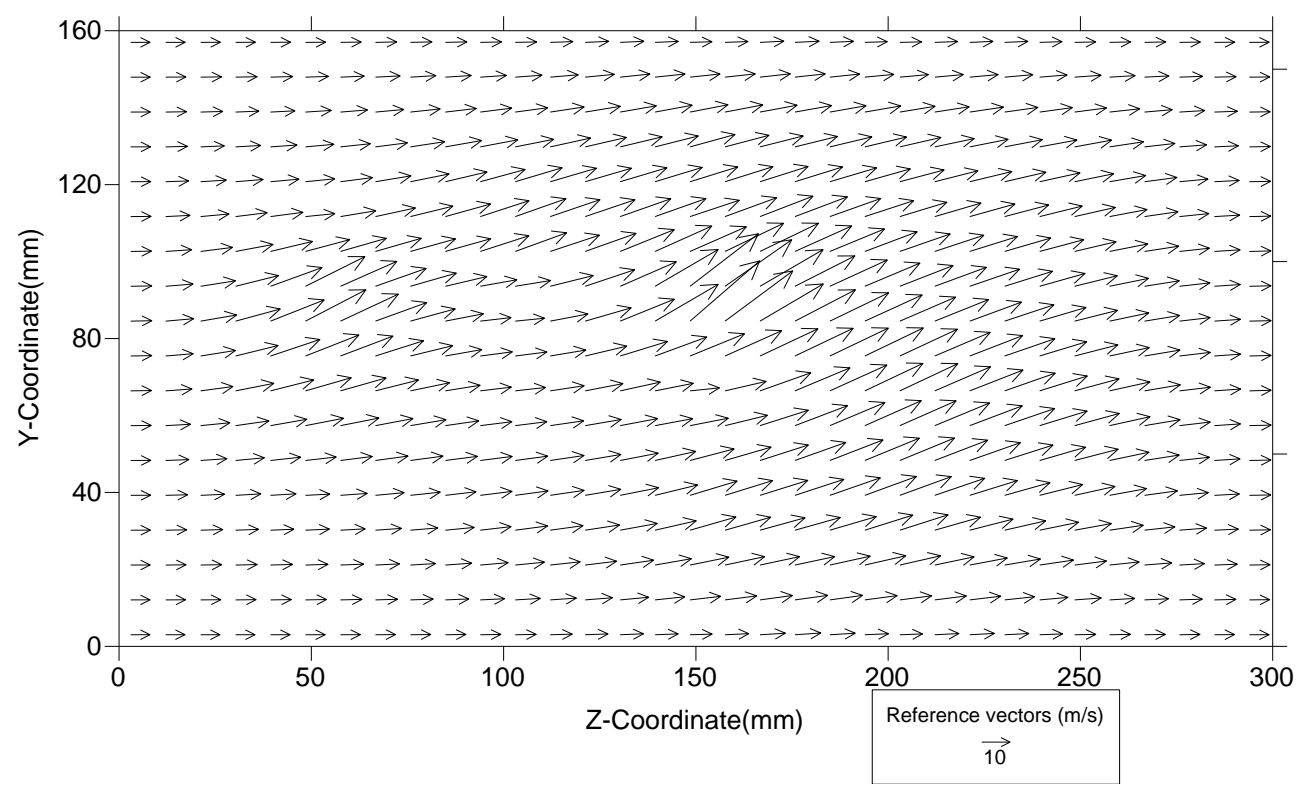

Figure 13 Secondary flow contour for the vehicle at $-30^{\circ}$ spoiler $+45^{\circ}$ co-rotating VGs.

Table 2 reflects the boundary layer measurements, in which the variation of total pressure and velocity with the distance. In upstream flow, maximum velocity and pressure is observed at $14 \mathrm{~mm}$, midstream has a pressure variation from $694.72 \times 10^{-6}$ to 778.8 $\mathrm{x} 10^{-6} \mathrm{MPa}$ and downstream is having velocity variation from 22.5 to $32.5 \mathrm{~m} / \mathrm{s}$.

Figure 14 (a) and (b) show the observations of flow separations on vehicle surface. Flow separations on the front part reflects that at $30 \mathrm{~m} / \mathrm{s}$ the flow cutting sides and shows position tufts movements in eddy form and at 10 and $20 \mathrm{~m} / \mathrm{s}$, the flow oscillate over the vehicle body and cutting the side flow show the smooth flow over vehicle body as the free stream flow features also change the angle of vehicle facing flow of incidence as $\left(+10^{\circ},+20^{\circ},+30^{\circ}\right)$ and $\left(-10^{\circ},-20^{\circ},-30^{\circ}\right)$. At $10^{\circ}$ and $20^{\circ}$ in both cases, windward and leeward side flow oscillate flow over vehicle body in as free stream flow features side flow show in upward direction flow. In the case of $+30^{\circ}$ and $-30^{\circ}$ of vehicle variation of 
flow show strong cross flow reverse flow, are indicated by the direction of the tufts. Tufts can also indicate regions of unsteady flow. The structure of the flow separations on the roof and rear part of vehicle body at different velocities show the flow cutting sides and shows position tufts movements in eddy form at 10 and $20 \mathrm{~m} / \mathrm{s}$.

Table 2. Boundary layer measurement

\begin{tabular}{ccccccccc}
\hline & Upstream & \multicolumn{9}{c}{ Midstream } & \multicolumn{3}{c}{ Downstream } \\
\hline $\begin{array}{c}\text { y } \\
(\mathrm{mm})\end{array}$ & $\begin{array}{c}\text { Total } \\
\text { pressure } \\
\mathrm{MPa}\left(10^{-6}\right)\end{array}$ & $\begin{array}{c}\mathrm{V} \\
(\mathrm{m} / \mathrm{s})\end{array}$ & $\begin{array}{c}\mathrm{y} \\
(\mathrm{m} \\
\mathrm{m})\end{array}$ & $\begin{array}{c}\text { Total pressure } \\
\text { MPa }\left(10^{-6}\right)\end{array}$ & $\begin{array}{c}\mathrm{V} \\
(\mathrm{m} / \mathrm{s})\end{array}$ & $\begin{array}{c}\mathrm{y} \\
(\mathrm{mm})\end{array}$ & $\begin{array}{c}\text { Total } \\
\text { pressure } \\
\mathrm{MPa}\left(10^{-6}\right)\end{array}$ & $\begin{array}{c}\mathrm{V} \\
(\mathrm{m} / \mathrm{s})\end{array}$ \\
\hline 0 & 0 & 0 & 0 & 0 & 0 & 0 & 0 & 0 \\
1 & 745.878 & 35.57 & 1 & 694.722 & 34.33 & 1 & 300.958 & 22.59 \\
2 & 750.68 & 35.68 & 2 & 700.7 & 34.47 & 2 & 354.466 & 24.52 \\
3 & 760.578 & 35.92 & 3 & 746.074 & 35.57 & 3 & 401.702 & 26.10 \\
4 & 757.442 & 35.84 & 4 & 778.806 & 36.35 & 4 & 469.91 & 28.23 \\
5 & 758.422 & 35.87 & 5 & 779.198 & 36.35 & 5 & 511.07 & 29.44 \\
6 & 763.42 & 35.98 & 6 & 788.508 & 36.57 & 6 & 545.86 & 30.43 \\
7 & 758.03 & 35.86 & 7 & 788.606 & 36.57 & 7 & 585.256 & 31.51 \\
8 & 764.106 & 36.05 & 8 & 788.802 & 36.58 & 8 & 591.136 & 31.66 \\
9 & 762.048 & 35.95 & 9 & 787.92 & 36.56 & 9 & 624.064 & 32.53 \\
10 & 763.224 & 35.98 & 10 & 788.018 & 36.56 & 10 & 619.85 & 32.42 \\
11 & 763.028 & 35.98 & 11 & 787.822 & 36.56 & 11 & 619.36 & 32.41 \\
12 & 762.538 & 35.96 & 12 & 788.116 & 36.56 & 12 & 618.87 & 32.40 \\
13 & 764.498 & 36.01 & 13 & - & - & 13 & 618.968 & 32.40 \\
14 & 764.89 & 36.02 & 14 & - & - & 14 & 591.626 & 31.68 \\
15 & 764.302 & 36.01 & 15 & - & - & 15 & 591.822 & 31.68 \\
- & - & - & - & - & - & 16 & 0 & 31.58 \\
\hline
\end{tabular}

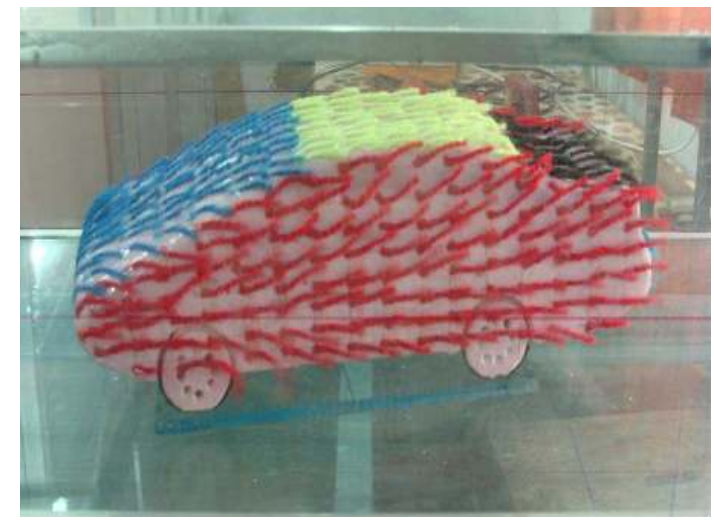

(a)

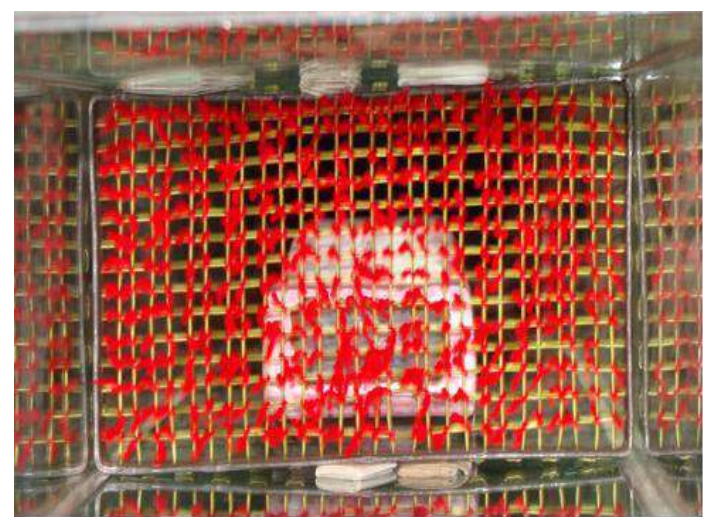

(b)

Figure 14. (a) Flow separations visualization on car surface. (b) Rear vortices flow visualization.

The flow oscillates flow over the vehicle body and cutting the side flow show the smooth flow over the vehicle body in the rear of the vehicle roof and the side wall of the vehicle. A verification study by flow visualization was performed for the optimum condition for minimum drag found during experimentation and the visualization depicted the certainty of the experimental results. 
Figure 15 (a) and (b) show dimension of the car model and spoiler considered for the study. The CFD analysis is conducted using ANSYS FLUENT ${ }^{\circledR}$ and car and spoiler models were made using Solid Works ${ }^{\circledR}$. Figure. 16 (a) shows the 3D CAD model of car and spoiler. Further, a virtual air-box similar to wind tunnel in experimentation was created. All the surfaces of wind tunnels were named so that appropriate boundary conditions similar to experimentation can be applied. The triangular shaped surface meshes were used for car model as they can easily adjust complex shapes as in Figure 16 (b).

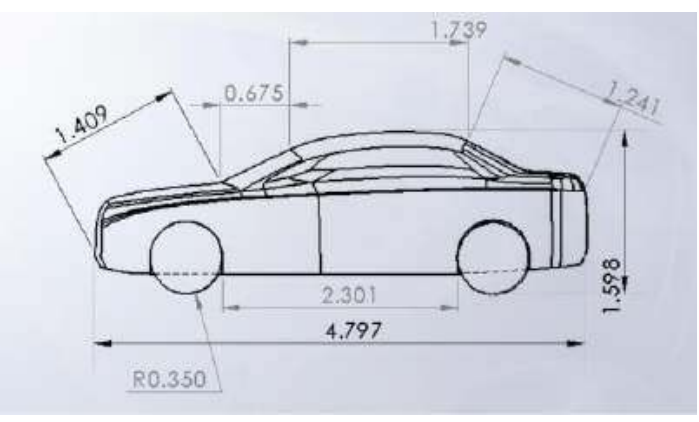

(a)

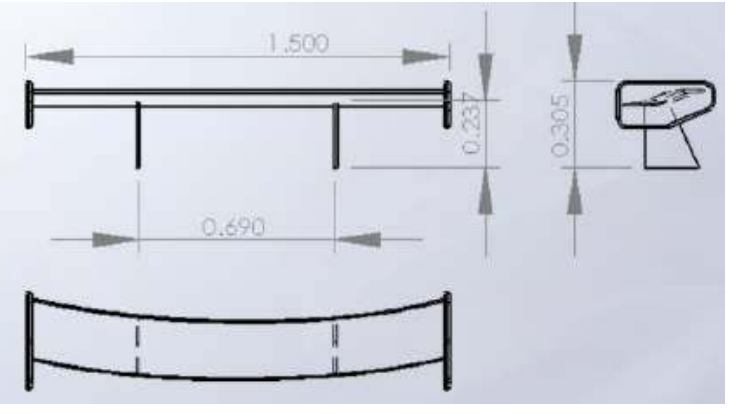

(b)

Figure 15. Dimensions of the (a) vehicle model and; (b) spoiler used (in $\mathrm{cm}$ ).

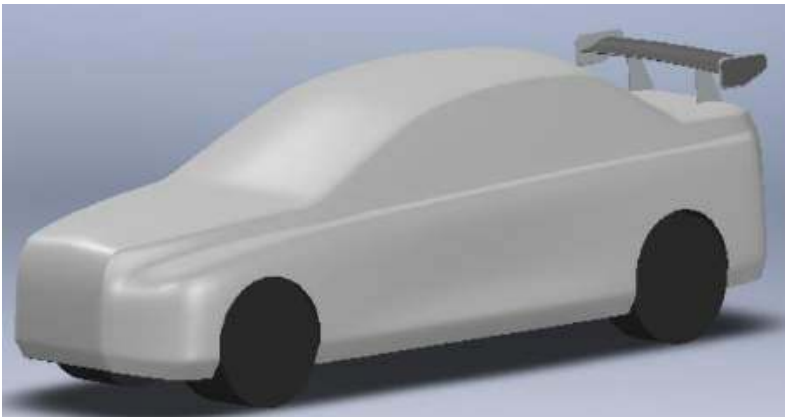

(a)

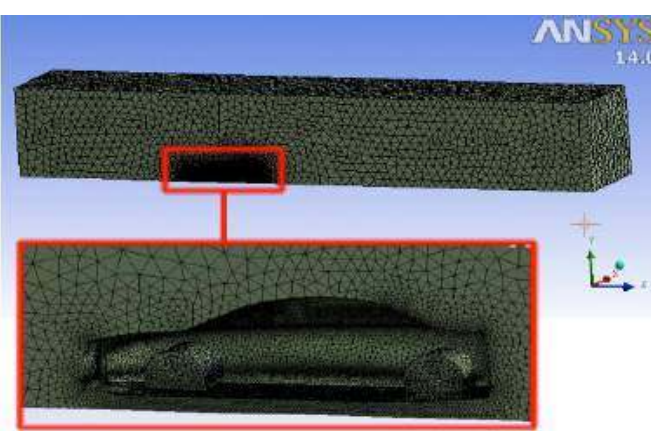

(b)

Figure 16. (a) Three-dimensional model of car and spoiler (b) Model meshing with modified size.

The boundary conditions were considered similar to experimentation; the density of air is taken as $1.175 \mathrm{Kg} / \mathrm{m}^{3}$ and kinematic viscosity was taken as $1.8247 \times 10^{-5} \mathrm{~kg} / \mathrm{ms}$; standard viscous and turbulence models (3D steady state, incompressible solution of the Navier-Stokes equations and realizable k- $\varepsilon$ model using non- equilibrium wall functions) were used as governing equations. Figure 17 (a) to (d) show the sample CFD output of two cases; with and without spoiler. The CD value was obtained for all 26 combinations similarly by numerical analysis and listed in Table 3 .

Table 3 reflects the values of $\mathrm{CD}$ obtained by CFD analysis is lesser that the experimentation, this could be due to the small blockage ratio of present in the wind tunnel and approximations in CFD analysis. Figure 18 shows the comparison between experimental and simulation results and it clearly reflect that the pattern followed by the $\mathrm{CD}$ in experimentation and numerical study is quite similar. The pattern of the values of $\mathrm{CD}$ shows numerical model presents sufficient evident to validate the experimental results. 

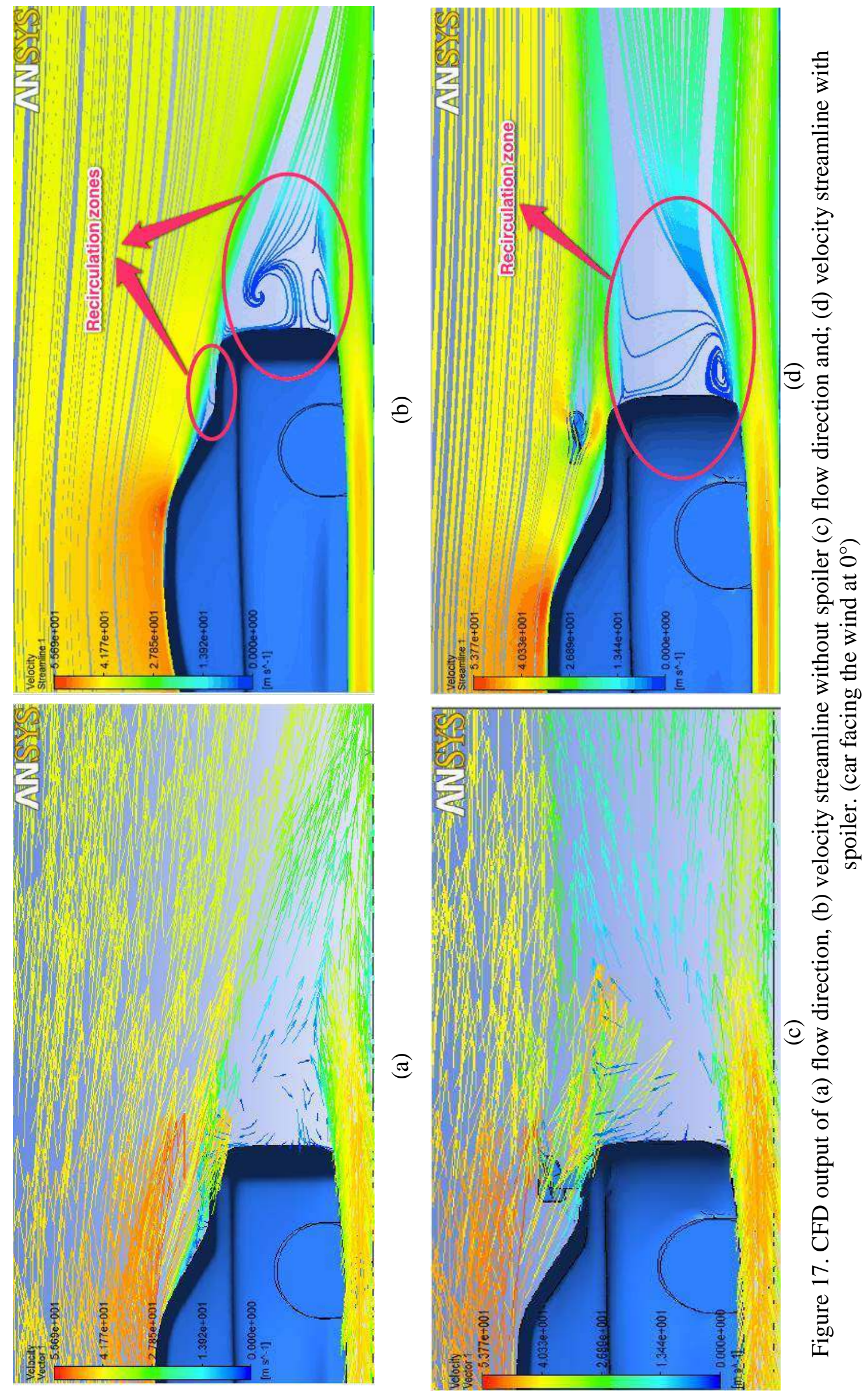
Table 3. Results of CFD analysis.

\begin{tabular}{clc}
\hline S. No. & Car Configuration & $\mathrm{Cd}$ \\
\hline 1 & Car facing the wind $(0)$ & 0.240 \\
2 & Car in Cross-wind $(+30)$ & 0.286 \\
3 & Car in Cross-wind $(-30)$ & 0.369 \\
4 & Car $(0)$ with Spoiler $(\alpha=0)$ & 0.119 \\
5 & Car $(0)$ with spoiler $(\alpha=+45)$ & 0.184 \\
6 & Car $(0)$ with spoiler $(\alpha=45)$ & 0.327 \\
7 & Car $(+30)$ with spoiler $(\alpha=0)$ & 0.147 \\
8 & Car $(+30)$ with spoiler $(\alpha=+45)$ & 0.239 \\
9 & Car $(+30)$ with spoiler $(\alpha=45)$ & 0.229 \\
10 & Car $(-30)$ with spoiler $(\alpha=0)$ & 0.296 \\
11 & Car $(-30)$ with spoiler $(\alpha=+45)$ & 0.105 \\
12 & Car $(-30)$ with spoiler $(\alpha=45)$ & 0.336 \\
13 & Car $(0)$ with spoiler $(0)$ and co-rotating VG & 0.172 \\
14 & Car $(0)$ with spoiler $(0)$ and counter-rotating VG & 0.235 \\
15 & Car $(0)$ with spoiler $(+45)$ and co-rotating VG & 0.206 \\
16 & Car $(-30)$ with spoiler $(+45)$ and co-rotating VG & 0.039 \\
17 & Car $(+30)$ with spoiler $(+45)$ and co-rotating VG & 0.264 \\
18 & Car $(0)$ with spoiler $(-45)$ and co-rotating VG & 0.289 \\
19 & Car $(-30)$ with spoiler $(-45)$ and co-rotating VG & 0.536 \\
20 & Car $(+30)$ with spoiler $(-45)$ and co-rotating VG & 0.318 \\
21 & Car $(0)$ with spoiler $(+45)$ and counter-rotating VG & 0.284 \\
22 & Car $(-30)$ with spoiler $(+45)$ and counter-rotating VG & 0.524 \\
23 & Car $(+30)$ with spoiler $(+45)$ and counter-rotating VG & 0.395 \\
24 & Car $(0)$ with spoiler $(-45)$ and counter-rotating VG & 0.355 \\
25 & Car $(-30)$ with spoiler $(-45)$ and counter-rotating VG & 0.433 \\
26 & Car $(+30)$ with spoiler $(-45)$ and counter-rotating VG & 0.351 \\
\hline & &
\end{tabular}

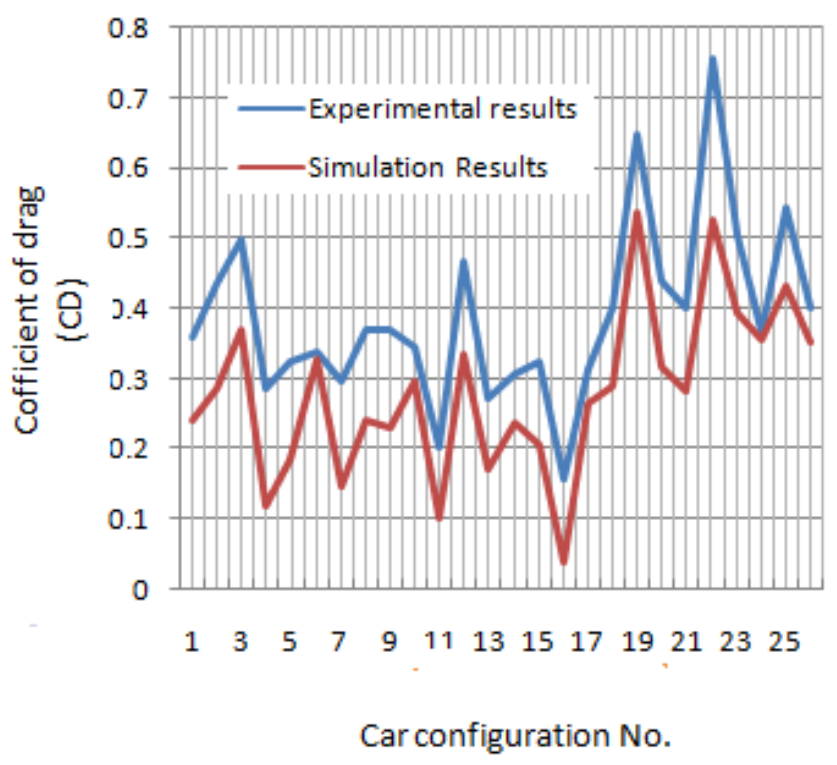

Figure 18. Comparison of experimental and simulation results. 


\section{CONCLUSION}

The minimum drag coefficient for the car model is found for twenty-six combinations obtained by varying the flow angles, spoiler angles and the orientations of VGs. At $\beta=$ $-30^{\circ}$ static pressure is increased significantly along the car roof, particularly at the rear due to the application of spoiler (at $\alpha=+45^{\circ}$ ) and co-rotating VGs. The suction reduces and static pressure values approach to zero close to the rear end of the model. The joint use of spoiler and VG reduces the flow separation zone and a positive pressure builds up on a small portion of the model roof near to the wind-ward side. Generally, the values of Cwp are positive and convincingly uniform over the side of the car facing the airflow. The negative Cwp is observed on the roof of the car, and the value of negative Cwp increases from the front to rear of the car. Large suction is observed as the value of $\beta$ increases from 0 to $+30^{\circ}$ in the front of the leeward wall.

The best arrangement with respect to Cwp rise (from -0.041 to +2.622) is observed as the car facing the wind at $\beta=0^{\circ}$ and spoiler at $\alpha=0^{\circ}$ with co-rotating VGs coupled at the upstream of the spoiler. A $36.36 \%$ additional area of the vehicle is facing the direct wind at cross-wind condition $\left( \pm 30^{\circ}\right)$ which result-in an increment of $38.61 \%$ in the drag coefficient. The VG accelerates the decelerating fluid that in turn delays the flow separation point towards the downstream. For the vehicle with $\beta=0^{\circ}$, a rear spoiler (at $\alpha$ $=+45^{\circ}$ ) and co-rotating VG lined in series reduces the value of $\mathrm{Cd}$ by $68.18 \%$. Flow visualization has satisfactorily validated the experimentally obtained optimum combination for the minimum $\mathrm{Cd}$ value. It was also found that secondary flow has insignificant effect in the presented cases.

The aerodynamics of high-speed passenger cars remains a relevant and interesting topic in the era of the conventional fuel crisis. Following recommendations are listed based on that further studies may be carried out in future. Detailed experiments can be conducted to find out forces and moments acting on the car body using digital straingauge balance system. A complete analysis may also be carried out to calculate various forces like side force, lift force, down force etc. The height of vortex generators may be varied to get the optimum drag reduction at higher wind velocity. Some sophisticated system like PIV, LDV can also be used for detailed flow measurement.

\section{ACKNOWLEDGEMENT}

Present work is supported by MNNIT Allahabad and Invertis University, Bareilly, (U.P.), India. The support of Prof. Anuj Jain and DR. A.R. Paul was appreciable during the experimental work.

\section{REFERENCES}

[1] Hucho W. Aerodynamics of road vehicles, Butterworth, London. 1997.

[2] Katz J. Race car aerodynamics: Designing for speed, Bentley Publishers, Cambridge, USA, 1995.

[3] Gilliéron P, Kourta A. Aerodynamic drag reduction by vertical splitter plates. Experiments in Fluids, 2010;48(1):1-16.

[4] Kourta A, Gillieron P. Impact of the automotive aerodynamic control on the economic issues. J. of Applied Fluid Mechanics, 2009; 2 (2): 69-75.

[5] Schlichting H, Gersten K. Boundary layer theory, 8th Edition, Springer Verlag, 2007. 
[6] Katz J. Aerodynamic of race cars. Annual Review of Fluid Mechanics, 2006;38:27-63.

[7] Gillhaus A, Hoffmann R. Directional stability, In: W. Hucho (Ed.) Aerodynamics of road vehicles, 4th edition, SAE International, Warrendale, 1998; 239-310.

[8] Toonder JM, Hulsen MA, Kuiken GDC et al. Drag reduction by polymer additives in a turbulent pipe flow: Numerical and laboratory experiments. Journal of Fluid Mechanics. 1997; 337: 193-231.

[9] Wei T, Willmarth WW. Modifying turbulent structure with drag-reducing polymer additives in turbulent channel flows. Journal of Fluid Mechanics. 1992; 245: 619-641.

[10] Min T, Choi H, Yoo JY. Maximum drag reduction in a turbulent channel flow by polymer additives. Journal of Fluid Mechanics. 2003; 492: 91-100.

[11] Bechert DW, Bruse M, Hage W et al. Experiments on drag reducing surfaces and their optimization with an adjustable geometry. Journal of Fluid Mechanics, 1997; 338: 59-87.

[12] Bechert DW, Bartenwerfer M. The viscous flow on surfaces with longitudinal ribs. Journal of Fluid Mechanics. 1989; 206: 105-129.

[13] Choi H, Moin P, Kim J. Direct numerical simulation of turbulent flow over riblets. Journal of Fluid Mechanics. 1993;255: 503-539.

[14] Mohammad NN, Saadat BM, Setareh S. Analysis of shear rate effects on drag reduction in turbulent channel flow with super hydrophobic wall. Journal of Hydrodynamics. 2013; 25(6): 944-953.

[15] Mohammad NN, Saadat BM, Setareh S, Alireza M. Drag reduction in a turbulent channel flow with hydrophobic wall. Journal of Hydrodynamics. 2012; 24(3): 458-466.

[16] Yan Y, Jing LUC, Ting SI et al. Water tunnel experimental investigation on the drag reduction characteristics of the traveling wavy wall. Journal of Hydrodynamics. 2011; 23(1): 65-70.

[17] Shupeng CAI, Guoyu JIN, Damei LI et al. Drag reduction effect of coupling flexible tubes with turbule- nt flow. Journal of Hydrodynamics. 2008; 20(1): 96100.

[18] Chengsheng WU, Shulong HE, Dexiang ZHU et al. Numerical simulation of microbubble flow around an axisymmetric body. Journal of Hydrodynamics. 2006; 18(3): 217-222.

[19] Geropp D, Odenthal, HJ. Drag reduction of motor vehicles by active flow control using the coanda effects. Experimental in fluids. 2000; 254:74-85.

[20] Koike M, Tsunehisa N, Naoki H. Research on aerodynamic drag reduction by vortex generators, Mitsubishi Motors Technical Review, 2004; 16:11-16.

[21] Singh SN, Rai L, Puri, P, Bhatnagar A. Effect of moving surface on the aerodynamic drag of road vehicles, Proceedings of I.Mech.E. (Part D), J. of Automobile Engineering, 2005;219:127-134.

[22] Desai M, Channiwala SA, Nagarsheth HJ. Experimental and computational aerodynamic investigations of car, Transaction on Fluid Mechanics, 2005; 3(4):359-367.

[23] Gohlke M, Beaudoin JF, Amielh M, Anselmet F. Experimental analysis of flow structures and forceson a 3D-bluff-body in constant cross-wind. Exp Fluids 2007; 43:579-594 DOI 10.1007/s00348-007-0341

[24] Beaudoin JF, Aider JL. Drag and lift reduction of a 3D bluff body using flaps, Experiments in Fluids, 2008; 44: 491-501. 
[25] Kourta A, Gillieron P, Impact of the Automotive Aerodynamic Control on the Economic Issues. Journal of Applied Fluid Mechanics, 2009;2 (2):69-75.

[26] Gillieron P, Chometon F. Modelling of stationary three-dimensional detached airflows around an Ahmed Reference Body, Third International Workshop on Vortex, ESAIM, Proceedings 1999;7: 173-182.

[27] Katz J. Race Car Aerodynamics- Designing for Speed, $1^{\text {st }}$ ed. Bently Publishers, 1995.

[28] Barbut D, Negrus EM. CFD analysis for road vehicles - case study, Incas Bulletin,2011;10:315-322. DOI: 10.13111/2066-8201.2011.3.3.2.

[29] Rouméas M, Gilliéron P, Kourta A, Drag Reduction by Flow Separation Control on a Car after Body, International Journal for Numerical Methods in Fluids, 2009; 60:1222-1240.

[30] Guilmineau E. Computational Study of Flow around a Simplified Car Body, Journal of Wind Engineering and Industrial Aerodynamics. 2008; 96:1207-1217.

[31] Islam MM, Mamun M. Computational Drag Analysis over a Car Body, International Conference on Marine Technology, Dhaka, Bangladesh, 2010.

[32] Krishnani PN. CFD study of drag reduction of a generic sport utility vehicle, Thesis for M.Sc. Mechanical Engineering, California State University, Sacramento, 2009.

[33] Adem FA. Drag Reduction of Pickup Truck Using Add-on Devices, Thesis for M.Sc. in Mechanical Engineering, California State University, Sacramento, 2009.

[34] Darko D, Dražan K, Marija Ž, Željko I, Tomislav B, CFD analysis of concept car in order to improve aerodynamics, Jármüiparilnnováció, University of Osijek, Croatia, 2011.

[35] Islam T, Hassan SMR, Ali M. Aerodynamic Drag of Racing Cars, Global Engineering, Science and Technology Conference, Dhaka, Bangladesh, 2012.

[36] DeGroot CT, Wang C; Floryan JM. Drag Reduction Due to Stream wise Grooves in Turbulent Channel Flow. J. Fluids Eng.2016; 138(12): 201-210.

[37] Perlin M, Dowling DR, Ceccio SL. Freeman Scholar Review: Passive and Active Skin-Friction Drag Reduction in Turbulent Boundary Layers. J. Fluids Eng. 2016; 138(9): 104-916.

[38] Andrade RM, Pereira AS, Soares EJ. Drag Reduction in Synthetic Seawater by Flexible and Rigid Polymer Addition Into a Rotating Cylindrical Double Gap Device. J. Fluids Eng. 2015; 138(2):101-110.

[39] Metka M, Gregory JW. Drag Reduction on the 25-deg Ahmed Model Using Fluidic Oscillators. J. Fluids Eng. 2015; 137(5):108-118.

[40] Lim GH, Choi HJ, Renou F, Roy AN. Effects of hydrophobic modification of xanthan gum on its turbulent drag reduction characteristics. Journal of Industrial and Engineering Chemistry. 2017; 54:146-150.

[41] Huang W, Langquan L, Li Y, Zhang T. Drag and heat flux reduction mechanism of blunted cone with aerodisks. Acta Astronautica, 2017; 138: 168-175. 